\title{
An Exploratory Investigation of the Ethical Behavior of Engineering Undergraduates
}

\author{
Trevor S. Harding, Donald D. Carpenter ${ }^{a}$, And Cynthia J. Finelli ${ }^{\mathrm{b}}$ \\ California Polytechnic State University, Lawrence Technological University ${ }^{a}$, \\ University of Michigan ${ }^{b}$
}

\begin{abstract}
BACKGROUND
Recent national reports have indicated the need for an increased emphasis on the ethical development of engineering undergraduates. Despite this call for increased focus on ethical development, little is known about how engineering students make ethical decisions or how these decisions are related to personal differences and environmental influences.
\end{abstract}

\section{PuRPOSE (HyPOTHESIS)}

This is an exploratory investigation to determine which demographic, academic, moral reasoning, and decision-making variables are predictive of the extent of test cheating among engineering undergraduates. Rather than beginning with a particular hypothesis, the study investigates predictive relationships between the variables described above and self-reported rates of test cheating among engineering undergraduates.

\section{DESIGN/METHOD}

Three hundred and eighty eight engineering undergraduates from three Midwestern U.S. institutions completed a survey based on a modified version of the theory of planned behavior as a conceptual framework. The three institutions are of different Carnegie classifications, sizes, missions, and institutional cultures.

\section{RESULTS}

Results indicate that our proposed model of ethical decision-making was successful in predicting the behavioral outcome with regard to college test cheating and there were observed significant differences in the level of cheating between institutions. However, institution as a variable was not a predictive of behavior.

\section{CONCLUSIONS}

The effect of institution on cheating was mitigated through other measured variables including past high school cheating, involvement in Pan-Hellenic groups, moral obligation, and perceived behavioral control. It is these underlying predictive variables that need to be addressed when engineering educators and student affairs staff consider the issue of unethical undergraduate behavior.

\section{KEYWORDS:}

decision-making, environment, ethics

\section{INTRODUCTION}

Reports from the past decade indicate the need for an increased emphasis on the ethical development of engineering undergraduates. The Carnegie Foundation report, entitled Educating Engineers: Designing for the Future of the Field (Sheppard, Macatangay, Colby, \& Sullivan, 2008), makes a strong argument for a national effort to improve ethics education within engineering. Similar arguments are found in the National Academy of 
Engineering's reports The Engineer of 2020 (National Academy of Engineering (NAE), 2004) and Emerging Technologies and Ethical Issues in Engineering (NAE, 2003), the National Science Foundation's Strategic Plan (NSF, 2006), and from the results of a series of Engineering Education Research Colloquies as reported in The Research Agenda for the New Discipline of Engineering Education (Adams et al., 2006).

Unfortunately, when considering reports of unethical behavior of engineering undergraduates, the evidence is not encouraging. Engineering undergraduates consistently report higher levels of cheating (a measure of unethical behavior) when compared with undergraduates in less professionally-oriented majors (Harding, Mayhew, Finelli, \& Carpenter, 2007; McCabe \& Trevino, 1997). In fact, in one of our recent studies, over 96\% of engineering undergraduates admitted to performing at least one academic act that the students themselves defined as either cheating or unethical (Carpenter, Harding, Finelli, Montgomery \& Passow, 2006). There is some evidence to suggest that this percentage would be even higher if institutional definitions of academic dishonesty were applied to the students' behavior.

This is an exploratory investigation whose focus is to determine which demographic, academic, moral reasoning, and decision-making variables are predictive of the extent of test cheating among engineering undergraduates. Rather than beginning with a particular hypothesis, we investigated predictive relationships between the variables described above and discrepancies observed in students' self-reported engagement in cheating in college. Ultimately we found that students enrolled at one specific institution reported significantly higher frequencies of cheating than at the other institutions. Our goal then, was to determine which of the variables mentioned previously might explain these higher levels of reported cheating.

Results we present here came from the Perceptions and Attitudes toward Cheating among Engineering Students (PACES-2) study, originally designed to develop and validate a model of ethical decision-making among engineering undergraduate students. In previous publications we reported on the PACES-2 data in the aggregate (Mayhew, Hubbard, Finelli, Harding \& Carpenter, 2009; Harding et al., 2007; Finelli, Harding \& Carpenter, 2007; Harding, Finelli, Carpenter \& Mayhew, 2006; Mayhew, Hubbard, Finelli, Harding, \& Carpenter, 2009). Here we present findings comparing engineering students from three institutions: Research State, Masters University, and Specialty Tech. All three institutions are located in the Midwest within a 100 mile radius of one another.

\section{SAMPLE DESCRIPTION}

We recruited engineering students from each of the three institutions for participation in the study with an overall goal of 400 participants. Students were selected at random and were recruited via email. Recruitment was limited to freshmen and seniors in order to compare students at the entry and exit points of their academic careers. As such, this is a cross-sectional investigation at a single point in time and not a longitudinal investigation. Students were provided a modest cash incentive to participate in the study. Response rates varied by institution-Research State 27.9\% (99 responses out of 355 recruited), Masters University $24.0 \%$ (88 out of 368), and Specialty Tech $53.2 \%$ (201 out 389) - with the survey only being administered once per institution.

A total of 388 engineering students participated in the study. More than half of the students in our sample (51.9\%) attended Specialty Tech, with the remaining respondents being almost equally split between the remaining two institutions. Table 1 provides a 
TABLE 1

Institution Profiles for Research State, Masters University, and Specialty Tech

\begin{tabular}{lccc}
\hline Sample Descriptives & $\begin{array}{c}\text { Research } \\
\text { State }\end{array}$ & $\begin{array}{c}\text { Masters } \\
\text { University }\end{array}$ & Specialty Tech \\
\hline Carnegie Classification & RU/VH & Master's L & Spec/Engg \\
Number of Respondents & 99 & 88 & 201 \\
Percentage of Study Sample (\%) & 25.6 & 22.5 & 51.9 \\
Response Rate (\%) & 27.9 & 24.0 & 52.0 \\
Female (\%)* & 36.4 & 16.1 & 15.9 \\
Average Age (years)* & 19.6 & 21.5 & 19.7 \\
Freshmen (\%) & 60.6 & 54.5 & 59.5 \\
Seniors (\%) & 32.2 & 40.9 & 38.5 \\
Transfer Students (\%)* & 11.2 & 21.6 & 5.5 \\
International Students (\%)* & 17.2 & 5.8 & 3.5 \\
Non-U.S. Citizens (\%)* & 19.2 & 7.1 & 3.6 \\
Fraternity \& Sorority Members (\%)* & 10.1 & 15.9 & 40.3 \\
Caucasian Students (\%)* & 69.7 & 89.8 & 88.1 \\
\hline
\end{tabular}

Note. ${ }^{*}$ Institutions differed statistically on this descriptive variable, $p<0.001$.

summarized comparison of the three institutions. Based on data included in the 2003 ASEE Profiles of Engineering and Engineering Technology Colleges (American Society for Engineering Education (ASEE), 2003), the data in Figure 1 appear to be representative of each institution's general engineering population. A brief description of each institution and its demographic profile follow.

\section{Research State}

At the time of the investigation. Research State was classified as a Research University with a very high activity level (RU/VH) (Carnegie Foundation for the Advancement of Teaching, 2009). Research State is a large public university with nearly 40,000 enrolled students. It has a long-standing tradition in the arts and sciences, with well-recognized programs in many professions including engineering. Carnegie lists the undergraduate population as primarily full-time, more selective, and having a low transfer-in rate.

Our sample of engineering students from Research State consisted of 99 respondents which accounted for $25.6 \%$ of the overall sample for the study. Research State was unusual in our study in that $36.4 \%$ of the respondents from this institution were female, a statistically $(p<0.001)$ higher representation than was present at the other universities. Furthermore, Research State was unique in that the percentage of international students in the sample (17.2\%) was nearly three times that of the institution with the next largest percentage of international students. The percentage of Caucasian students in the Research State sample (69.7\%) was substantially lower than the other two institutions.

\section{Masters University}

The Carnegie Classification System classifies Masters University as a Large Masters level institution (Carnegie Foundation for the Advancement of Teaching, 348 
2009). The school's primary focus is on professional programs with a majority of the student body enrolled in engineering and architecture programs. Overall, the institution has a high undergraduate enrollment profile with a large number of part-time and transfer students.

Within our sample, 88 engineering undergraduates (22.6\% of the total sample) attended Masters University. The most unique characteristic of Masters University was that the average age of respondents was nearly two years higher than the other two institutions in our sample $(p<0.001)$. This is not surprising given the large number of transfer-in (21.6\% of sample) and part-time students who would normally be older than traditional students and the fact that the respondent profile consisted of slightly more seniors than the other two schools.

The sample from Masters University was predominately white and male, with lower representation from ethnic minorities, international students, and women compared to the other institutions in the study. This is consistent with the student body at large. It should also be noted that $83 \%$ of Masters University students held part-time jobs for at least three months per year while enrolled at the school (Harding, Carpenter, Finelli \& Passow, 2004).

\section{SpecialtyTech}

The Carnegie Classification system (Carnegie Foundation for the Advancement of Teaching, 2009) classifies Specialty Tech as a Special Focus institution with a specialization in engineering. Specialty Tech has approximately 2,000 students, almost all of which are undergraduates. The student body consists primarily of full-time traditional students, with relatively few transfers from other institutions (5.5\%).

Specialty Tech accounted for 201 respondents within our sample, or $51.9 \%$ of the total. The higher response rate is thought to be a result of a very convenient survey administration time and location for the students. Perhaps the most defining characteristic of Specialty Tech was the large number of students who participated in fraternities or sororities (40.3\%), nearly four times the rate of participation at Research State. Specialty Tech is also known for its extensive co-operative education program. As such nearly all respondents reported working in an engineering position for six months of the year throughout their undergraduate education. Similar to Masters University, the sample from Specialty Tech was a fairly homogenous white and male group.

\section{RESEARCH INSTRUMENTS}

The behavioral sciences institutional review board, or its equivalent, at each institution reviewed and approved all instruments used in this study. The instruments consisted of the Perceptions and Attitudes toward Cheating among Engineering Students Survey (PACES-2; Harding, et al., 2007) and the Defining Issues Test (DIT-2; Rest, Narvaez, Thoma \& Bebeau, 1999). The PACES-2 Survey includes demographic questions, behavioral measures, and items meant to assess several constructs that underlie an individual's decision to engage in college cheating. The DIT-2 is a multiple-choice test that is based on Kohlberg's Theory of Moral Development (Kohlberg, 1981) and provides a measure of an individual's moral reasoning from a social justice perspective. Participants completed these instruments during a three hour time-frame in a large room at each of the three institutions. Besides the participants no one else, including ourselves, was permitted in the room. 
The main goal of this study was to investigate student ethical behavior. However, the measurement and study of ethical behavior is a challenging proposition, given the difficulty in developing valid instruments that are both common and recent for the population of interest. To deal with this challenge, we developed a research design focused on using self-reports of undergraduate engineering students' engagement in academic dishonesty (i.e., cheating) as a target for examination of their ethical decision-making and ethical behavior while in college. Most importantly, this ethical decision is one that requires students to consider a behavior they know to be in violation of established policies, codes, and, in some cases normative value systems. Thus, academic dishonesty represents an authentic experience by which ethical decision-making and behavior can be studied among this population.

The PACES-2 Survey underwent pilot testing at Research University to develop reliable, internally-consistent scales and to identify shortcomings in study protocols. We followed this pilot testing with a test-retest protocol to establish the temporal stability of instrument items. The final phase of the study involved the full administration of the PACES-2 and DIT-2 survey instruments during several sessions (Finelli, Szwalek, Harding \& Carpenter; 2005).

We have broken the study variables into five groups: behavioral, demographic, academic, moral reasoning, and decision-making. In the following sections we describe each of these variable groups, with specific variable names appearing in italics. Table 2 provides a summary of the study variables.

\section{Behavioral Variables}

The primary behavioral outcome variable investigated for this study was self-reported test cheating in college (College cheat) and is included in the PACES-2 Survey. In previous studies (Passow, Mayhew, Finelli, Harding \& Carpenter, 2006) we have found the context of test cheating to be more suitable for statistical comparisons of sub-groups within our study sample than other contexts (e.g., homework cheating). Using a fivepoint Likert scale, we asked respondents to answer "During the previous academic term in college, how frequently did you cheat on in-class tests or exams?" Responses to these items included: "Never (1)," "A few of the times I took a test or exam (2)," "About half the times I took a test or exam (3)," "Almost every time I took a test or exam (4)," and "Every time I took a test or exam (5).”

The PACES-2 survey included a similar item to measure the frequency with which students cheated on tests during a typical term in high school (HS cheat): "During an average academic term in high school, how frequently did you cheat on in-class tests or exams?" This variable is not an outcome variable, but is instead intended as a measure of past behavior among the study participants. Subsequent references to students cheating will refer to College cheat unless otherwise indicated.

It is worth noting that the wording of these items does not define "cheating" for the respondent. It is a difficult task to define cheating for the purposes of a survey given the myriad situational variables that influence people's definitions of cheating. From our experience, a preferred approach is to let the individual respondents define cheating for themselves since this is the context from which they are making decisions. As such, the items described above measured the extent to which the respondents acknowledged engaging in a behavior they recognize as cheating and (by assumption) unethical. Our past research has shown that students overwhelmingly describe academically dishonest behaviors involving tests as both cheating and unethical (Carpenter et al., 2006). In this 
TABLE 2

Summary of Study Variables

\begin{tabular}{|c|c|c|}
\hline Group & Variable Name & Description \\
\hline $\begin{array}{l}\text { Behavioral } \\
\text { Outcome }\end{array}$ & College Cheat & $\begin{array}{l}\text { Frequency of test cheating during the previous academic } \\
\text { term in college ( } 1 \text { item; } 5 \text {-point Likert - median split) }\end{array}$ \\
\hline \multirow{4}{*}{$\begin{array}{l}\text { Demo- } \\
\text { graphic }\end{array}$} & Age & Respondent's age ( 1 item) \\
\hline & $\operatorname{Sex}$ & Respondent's sex (1 item; Male/Female) \\
\hline & Citizenship & $\begin{array}{l}\text { Identifies respondent as U.S. citizen or non-U.S. citizen } \\
\text { ( } 1 \text { item) }\end{array}$ \\
\hline & Caucasian & $\begin{array}{l}\text { Caucasion/not-Caucasion (African-American, Asian- } \\
\text { American, Hispanic, Native American) (1 item) }\end{array}$ \\
\hline \multirow[t]{6}{*}{ Academic } & Institution & $\begin{array}{l}\text { One of three institutions from which students were } \\
\text { recruited ( } 1 \text { item) }\end{array}$ \\
\hline & Class Level & Freshmen, sophomore, etc. (1 item) \\
\hline & International & Is the student an international student? ( 1 item; yes/no) \\
\hline & Transfer & $\begin{array}{l}\text { Did student transfer from a two-year college to institution? } \\
\text { (1 item; yes/no) }\end{array}$ \\
\hline & Scholarship & $\begin{array}{l}\text { Extent that scholarship pays for student's college education } \\
\text { (1 item; 4-point Likert) }\end{array}$ \\
\hline & Pan-Hellenic & $\begin{array}{l}\text { Extent that student participates in fraternity or sorority } \\
\text { (1 item; } 5 \text {-point Likert) }\end{array}$ \\
\hline \multirow[t]{3}{*}{$\begin{array}{l}\text { Moral } \\
\text { Reasoning }\end{array}$} & N2 Score & $\begin{array}{l}\text { Respondent's preference for principled reasoning and re- } \\
\text { jection of personal interest reasoning making this a single } \\
\text { variable as determined by individual responses on the } \\
\text { DIT2 instrument ( } 1 \text { item; percentage score from } 0-100 \text { ) }\end{array}$ \\
\hline & Anti-Social & $\begin{array}{l}\text { Measure of respondent's anti-establishment attitude. } \\
\text { (4 items; 4-point ranking score) }\end{array}$ \\
\hline & Cons/Trans & $\begin{array}{l}\text { Establishes whether an individual is firmly consolidated } \\
\text { within a particular schema of moral reasoning, or transi- } \\
\text { tioning between moral schema ( } 1 \text { item; consolidated or } \\
\text { transition) }\end{array}$ \\
\hline \multirow[t]{5}{*}{$\begin{array}{l}\text { Decision- } \\
\text { making }\end{array}$} & Intention & $\begin{array}{l}\text { Measures an individual's expectation of following through } \\
\text { on a decision to engage in a specific behavior ( } 5 \text { items; } \\
5 \text {-point Likert) }\end{array}$ \\
\hline & Attitude & $\begin{array}{l}\text { Measures an individual's disposition to respond favorably } \\
\text { to the behavior in question ( } 5 \text { items; } 7 \text {-point semantic dif- } \\
\text { ferential) }\end{array}$ \\
\hline & Subjective Norm & $\begin{array}{l}\text { Extent to which individual's believe that important others } \\
\text { would approve or disapprove of their engaging in the be- } \\
\text { havior in question ( } 8 \text { items; } 5 \text {-point Likert) }\end{array}$ \\
\hline & $\begin{array}{l}\text { Perceived Behavioral } \\
\text { Control }\end{array}$ & $\begin{array}{l}\text { Perceived ease or difficulty of performing the behavior in } \\
\text { question ( } 4 \text { items; } 5 \text {-point Likert) }\end{array}$ \\
\hline & Moral Obligation & $\begin{array}{l}\text { Responsibility to perform, or refuse to perform, the behav- } \\
\text { ior in question ( } 3 \text { items; } 5 \text {-point Likert) }\end{array}$ \\
\hline $\begin{array}{l}\text { Past } \\
\text { Behavior }\end{array}$ & HS Cheat & $\begin{array}{l}\text { Frequency of test cheating during an average academic } \\
\text { term in high school ( } 1 \text { item; } 5 \text {-point Likert - median split) }\end{array}$ \\
\hline
\end{tabular}




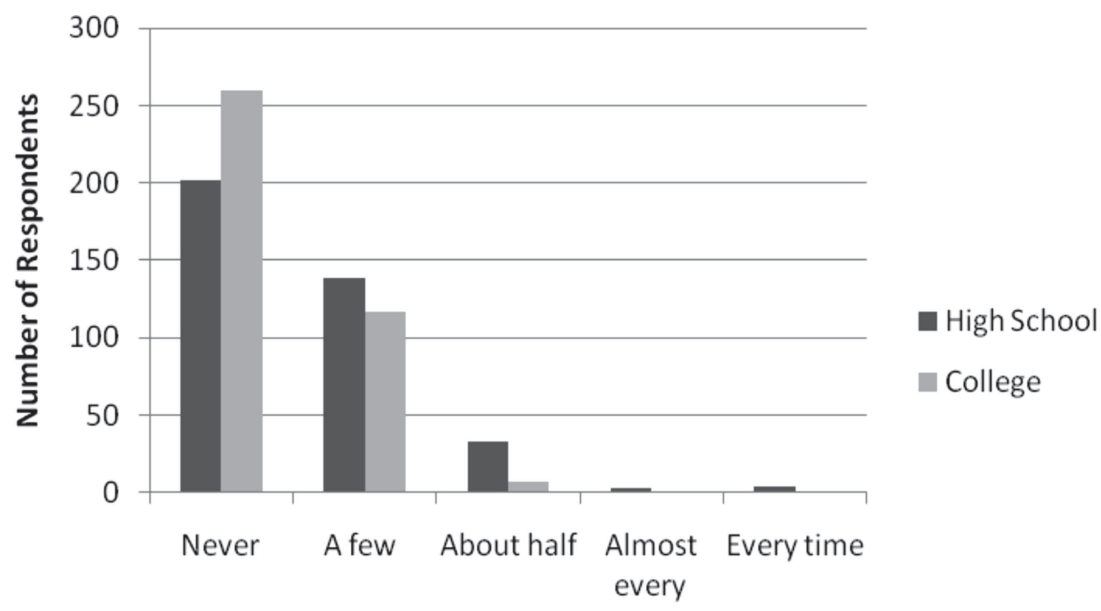

\section{Frequency of Test Cheating}

FIGURE 1. Distribution of respondents self-reported college and high school cheating frequencies.

way, the measures of cheating behavior used in this study are conservative but are assessing an act that the respondent defines as unethical, thereby avoiding the difficulty of defining "cheating."

Further, the wording for these items requires the respondent to consider the frequency with which they cheated relative to the opportunities available, thus accounting for potential differences in number of opportunities to engage in cheating that students may have experienced. Respondents were also asked to indicate the number of times they had cheated on a test in the last term in separate survey items. The frequency and number items correlate highly (0.90), providing support for the validity of the frequency item. We did not, however, use the items related to "number of times" for further analysis.

Due to the non-normal distribution of the behavior variables (Figure 1), we attempted transformative procedures, including logit and square root. Because these attempts did not normalize the variable distributions, we performed a median split. The majority of respondents indicated that they had never cheated on a test in the past academic term and were considered 'non-cheaters' for the purposes of this study. Conversely, those who admitted to cheating at least 'a few of the times' they took a test were referred to as 'cheaters.' Respondents categorized into the 'cheaters' group constituted $32.2 \%$ of the sample. There was no difference in the median split for HS cheat among the institutions, but a significantly higher percentage of students at Research State fell into the 'non-cheater' category. The median splits of the HS cheat and College cheat variable were used for all subsequent analyses described in this study.

\section{Demographic Variables}

The instruments included four demographic variables meant to capture differences between the three institutions considered in this study and for use as predictor variables during analysis. Demographic variables included age, sex, citizenship (U.S. or other), and 
ethnicity (African-American, Asian-American, Hispanic, Native America, or Caucasian). Given the small number of non-Caucasian participants in this study, we grouped the ethnicity variables into one dichotomous dummy variable (Caucasian, no $=1$ ) which indicated whether someone was Caucasian or not.

\section{Academic Variables}

The six academic variables include the student's institution and class level, whether or not they had transferred from a two- or four-year college (transfer), and whether they were an international student (international). In addition, we asked respondents to indicate the extent to which their education was being paid through scholarship (scholarship) and the extent of their participation in fraternity or sorority activities (Pan-Hellenic). We include the latter two variables here because they were found to be important predictor variables in previous studies we conducted (Harding et al., 2007). The variable scholarship was measured using a four-point Likert scale in which respondents were asked to indicate how much scholarship money contributed to paying for their college education where responses included "All," "Most," "Some," and "None." Pan-Hellenic was measured with a fivepoint Likert scale in which individuals were asked to indicate how much time per week they spent contributing to membership in a Greek organization where responses included "Not in a sorority or fraternity," "0-5 hrs per week," "6-10 hours per week," "11-20 hours per week," and "> 20 hours per week."

\section{Moral Reasoning Variables}

Rest and colleagues (Rest \& Narvaez, 1994; Rest \& Narvaez, 1998; Rest, Narvaez, Thoma \& Bebeau, 1999) originally developed the DIT-2 based on Kohlberg's theory of moral development (Kohlberg, 1981). Kohlberg's theory suggests that individuals who adopt a principled approach to resolving moral issues understand fairness and justice as systems that serve anonymous others. The DIT-2, and its predecessor the DIT, purport to measure only the moral reasoning component of what constitutes moral development; as such it is susceptible to change over time. The DIT-2 is designed to assess how respondents rate and rank prescribed statements most closely aligned with their reasoning when faced with five hypothetical moral dilemmas. The DIT-2 is generally considered to be among the most valid instruments for measuring moral reasoning aptitude (Rogers, 2002). For this study, we use three variables from the DIT-2 - the N2 score, anti-social measure, and cons/trans index. These variables, and others, are derived from respondents' assessments of four moral dilemmas in the DIT-2. The most well-known dilemma within the DIT-2 is the so-called "Heinz" dilemma. In this case, a husband is faced with the choice of stealing drugs from a local pharmacy or watching his gravely ill wife die. Respondents are asked to determine whether the husband is morally justified in stealing the drug. Respondents are presented with a variety of considerations such as "Whether the druggist is going to be allowed to hide behind a worthless law which only protects the rich anyhow." Respondents are then asked to rank the importance of these statements relative to one another.

The $N 2$ score provides an indication of the extent to which an individual uses principled reasoning in their moral decision making and avoids the use of pre-conventional, self-interested reasoning. Higher N2 scores reflect an individual's increased capacity for reasoning about moral issues based on a system of fairness that serves the public good; lower N2 scores tend to reflect reasoning about moral issues from a self-serving understanding of fairness.

The DIT-2 also includes an anti-social measure that reflects an individual's anti-establishment attitude. Typically individuals with a low anti-social measure can have what is 
referred to as a conventional law and order perspective to moral reasoning, typical of most adults. However, anti-social individuals are distinguished in that their criticisms of authority are not supported with constructive solutions. The anti-social measure is a summation of an anti-social item from each of the four DIT-2 dilemmas.

In addition, the DIT-2 includes an index (cons/trans) that stratifies students into two categories-those in consolidation and those in transition. Students in consolidation tend to resolve moral dilemmas from a consistent and stable position within Kohlberg's stage theory of moral development (Thoma \& Rest, 1999). Respondents in transition are thought to be vacillating between the use of lower and higher stages of cognitive reasoning in their moral decision-making. Such transitional states are common as individuals progress through the moral development stages.

\section{Decision-Making Variables}

The PACES-2 Survey includes a number of items intended to assess various aspects of the theory of planned behavior, and we used five variables in the model presented in this paper. According to Ajzen's theory (2002a) of planned behavior, three underlying constructs determine an individual's intention to perform a behavior: (1) their attitude toward the behavior (attitude), (2) perceived social pressures to engage in or not engage in the behavior (subjective norm), and (3) perceived ease of performing the behavior (perceived behavioral control). In the aggregate, these components directly influence an individual's intention to complete a behavior (in this case College cheat), and intention in turn influences whether an individual ultimately engages in the behavior as shown in Figure 2. In circumstances in which an individual perceives that they have some manner of volitional

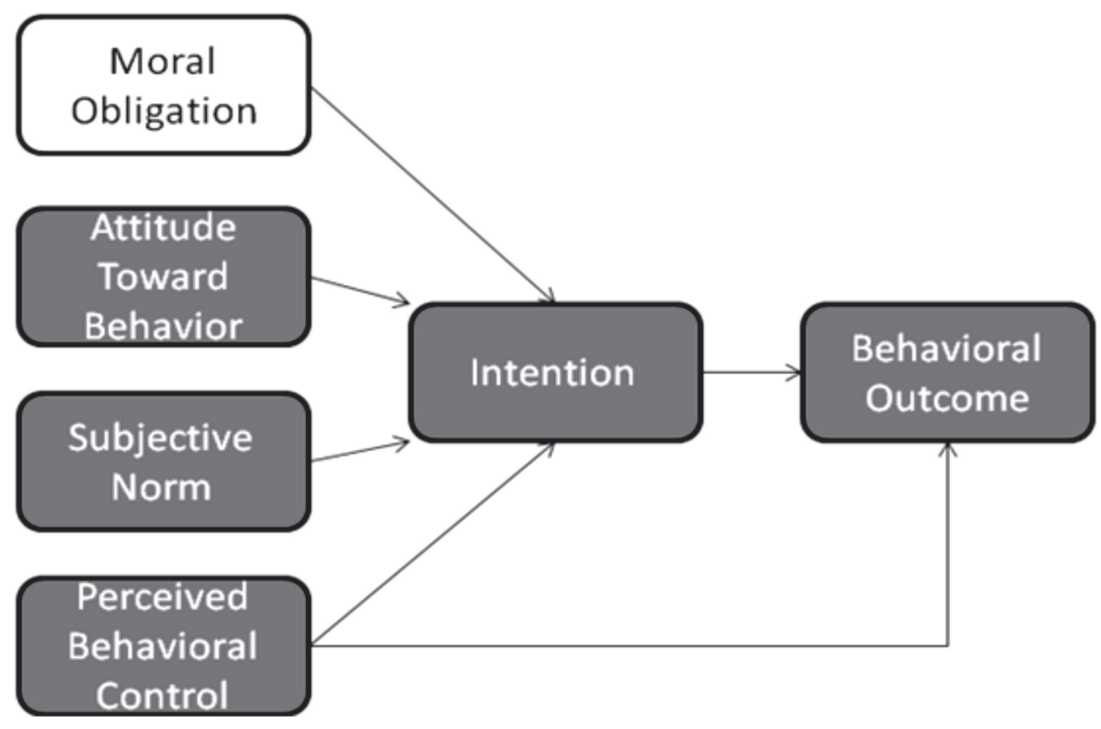

FIGURE 2. Modified version of Ajzen's theory of planned behavior (Ajzen, 2002a). The original model is shown in the shaded boxes. 
control over their own environment, perceived behavioral control is expected to have some influence on the behavioral outcome as well.

We have modified the theory of planned behavior to include moral obligation that may be defined as the "responsibility to perform, or refuse to perform, a certain behavior" (Ajzen, 1991, p. 199). Given that cheating is a moral issue, and that moral norms are likely to play a pivotal role in instances of ethical decision-making (Conner \& Armitage, 1998), it is included here as an additional construct. Our previous research found through structural equation modeling that the modified form of the theory of planned behavior is a viable framework for understanding the psychological mechanisms that students use when deciding to cheat (Mayhew, et al., 2009). We also found that the influence of the underlying constructs of the theory of planned behavior are relatively stable across different contexts (e.g., cheating on tests versus cheating on homework) associated with decision making (Harding, et al., 2007). Furthermore, differences in construct scores were correlated to differences in reported frequencies of cheating across varied disciplines (e.g., humanities and engineering), providing evidence for the concurrent validity of these constructs.

Each of the five constructs of the modified theory of planned behavior consisted of multiple items (see Table 2), of which all but one used 5-point Likert scales (strongly disagree to strongly agree). Attitude used a series of five 7-point semantic differential scales (e.g., good/bad) established as most salient to our sample through pilot testing. We scored all items in such a way that a higher score would be predictive of a greater likelihood to engage in the outcome behavior so that all underlying constructs of the theory of planned behavior would have the same directionality - an increase in the construct scale relates to an increase in intention and thus behavior. We conducted confirmatory factor analysis on items comprising the constructs, and we generated scales by averaging the item scores within these factors. All scales had sufficient internal reliability with Chronbach's alpha scores of 0.66 (perceived behavioral control) to 0.91 (intention).

\section{ANALYSIS OF STUdy VARIABLES}

\section{Behavioral Differences Across Institutions}

Of all respondents, $47.1 \%$ indicated that they had cheated on tests at least a few of the times they took a test during a typical academic term in high school, while $10.4 \%$ reported cheating about half the time. The percentages for college were lower with $32.5 \%$ of respondents indicated cheating on a test at least a few of the times they took a test during the most recent academic term in college and 1.9\% reported cheating about half the time. While this reduction in reported frequency of cheating is encouraging, we still found that nearly one-third of engineering undergraduates admitted to cheating on a test in one academic term. These numbers should be viewed with caution, however, as they are biased toward respondents from Specialty Tech who constitute roughly half of the sample.

Indeed, when we compared frequencies of cheating across institutions, we found two intriguing results. First, the percentages of students who were classified as 'cheaters' in both high school and college differed across all three institutions (see Figure 3). Second, the reduction in this cheating from high school to college also differed. At Research State $37.8 \%$ of respondents reported cheating at least a few of the times they took a test in high school. By comparison, this number is $52.3 \%$ and $49.2 \%$ of participants at Masters University and Specialty Tech respectively. Although more respondents at Masters University and Specialty Tech were classified as 'cheaters' at the high school level, the differences between institutions were not statistically significant $(\chi 2=5.093, d f=2, p=0.078)$. 


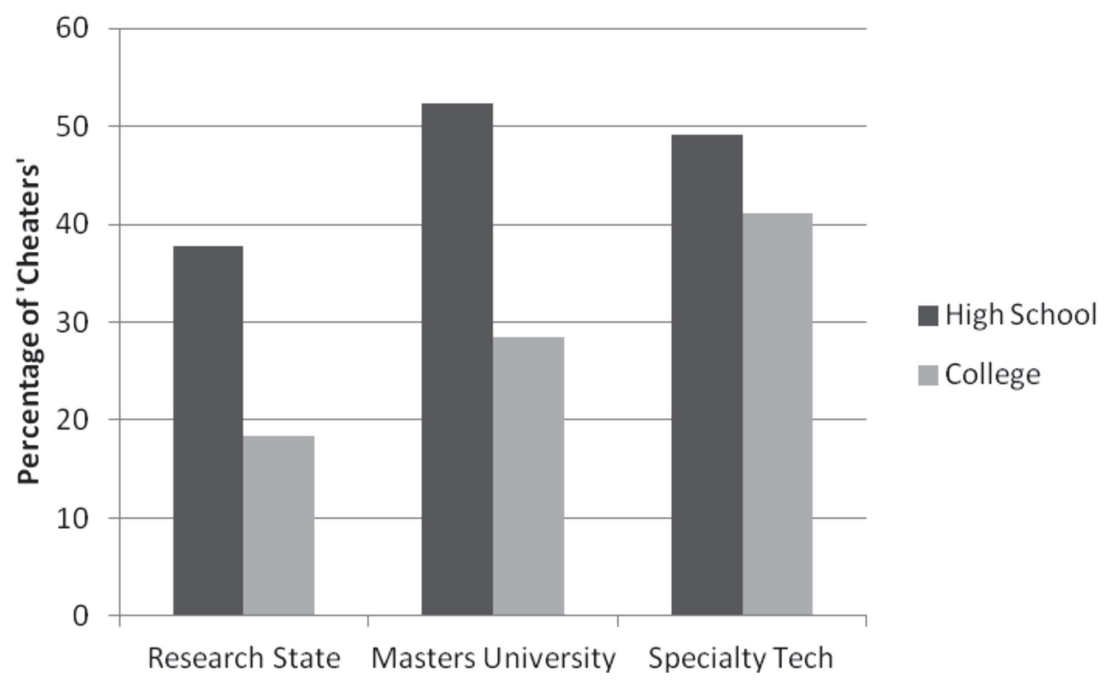

FIGURE 3. Percentage of respondents classified as 'cheaters' in high school and college across all three institutions. There were no statistically significant differences in high school cheating across the institutions. Specialty Tech showed a statistically higher percentage of college cheaters than the other schools. All institution specific reductions in cheating from high school to college were statistically significant at $p<0.05$.

In the case of college test cheating, however, significant differences did appear. As shown in Figure 3, only $18.4 \%$ and $28.4 \%$ of students at Research State and Masters University, respectively, were classified as 'cheaters' in college. However, $41.2 \%$ of students at Specialty Tech reported cheating at least a few of the times they took a test in college. These differences in college test cheating across institution were significant $(\chi 2=16.435$, $d f=2, p<0.001)$.

At all institutions the number of students classified as 'cheaters' in college is lower than the number classified as 'cheaters' in high school. The percentages of students identified as 'cheaters' were reduced nearly by half at both Research State $(Z=-3.922, p<0.001)$ and Masters University $(Z=-4.017, p<0.001)$. At Specialty Tech, on the other hand, the reduction in self-reported test cheating from high school to college was significant $(Z=$ $-2.109, p=0.035)$ but was smaller in its magnitude by comparison to the other institutions.

These data led us to our primary focus for this investigation: to determine which demographic, academic, moral reasoning, or decision-making variables might explain why the extent of college test cheating among respondents from Specialty Tech is so much higher compared to that at Research State and Masters University.

\section{Demographic Variables}

The age of respondents was related to their classification as 'cheaters' or 'non-cheaters' in college $(p=0.026)$. 'Cheaters' tended to be slightly younger on average (19.6 yrs) compared to their counterparts $(20.4 \mathrm{yrs})$. Although this difference was statistically significant 


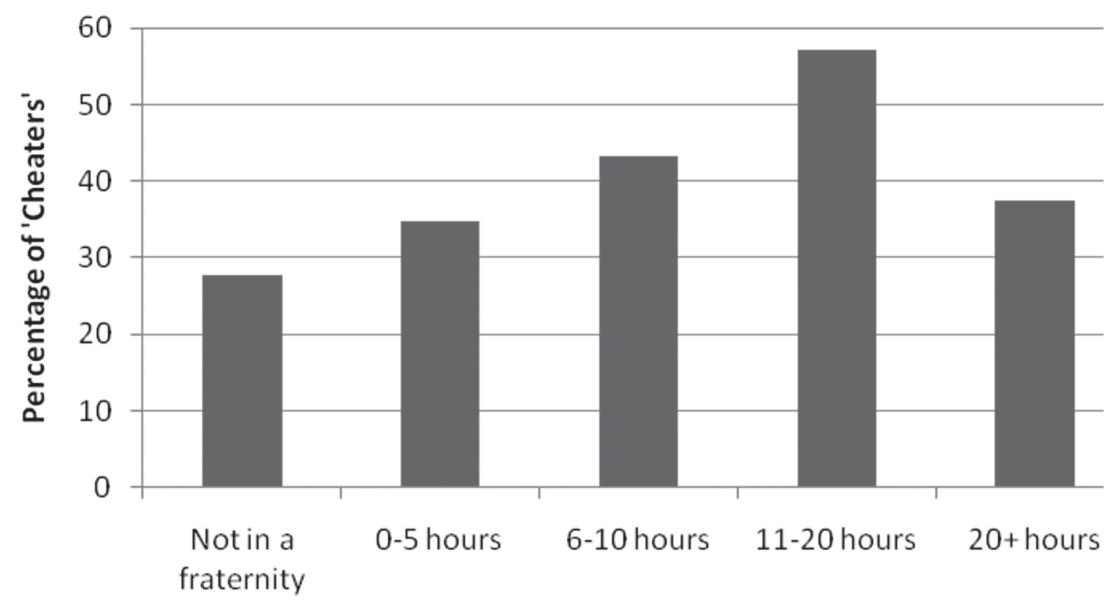

Time spent on fraternity or sorority activities per week

FIGURE 4. Effect of fraternity or sorority participation on percentage of respondents classified as 'cheaters.'

owing to the large sample size, it was not a particularly large difference. There were no observed effects on cheating classification for any of the remaining demographic variables (sex, citizenship, or Caucasian).

\section{Academic Variables}

Freshmen were slightly more likely to fall into the category of 'cheaters' (35.1\%) as compared to seniors (28.5\%). This difference is expected given that we previously observed differences in the average age of 'cheaters' and 'non-cheaters.' Since we surveyed only freshmen and seniors, we expect that any relationship between age and cheating would parallel the effect of class level.

The extent to which students participated in Pan-Hellenic activities had the largest effect on whether participants were classified as 'cheaters,' as illustrated in Figure 4. There is a distinct, non-linear trend between time spent in Pan-Hellenic activities and the percentage of students classified as 'cheaters' in college. The lowest percentage of classified 'cheaters' seemed to be non-members. For those who defined themselves as members in a PanHellenic activity, the percentage of self-reported cheaters within the sample increased almost linearly. However, the percentage of 'cheaters' within the group of respondents spending the greatest amount of time on Pan-Hellenic activities (20+ hours per week) was lower than expected and was roughly equivalent to that for students who spent 0 to 5 hours per week on these activities.

These results should be interpreted with caution given the relatively small numbers of students in the sample $(n=16)$ who participated in fraternity/sorority activities for more than 20 hours per week. It should also be said that the distribution shown in Figure 4 generally holds for all three institutions. Given the small sample sizes within each institution, however, statistical comparisons are not possible. Finally, there were no statistical differences in the number of respondents classified as 'cheaters' based on 
whether they were a transfer student or international student, or the extent to which they relied on scholarship funds to support their education.

\section{Moral Reasoning Variables}

The N2 score differed considerably between 'cheaters' and 'non-cheaters' $(t=3.684$, $d f=364, p<0.001)$. Respondents classified as 'non-cheaters' had an average $N 2$ score of $31.1(\sigma=13.1)$, while the average N2 score for 'cheaters' was $25.7(\sigma=13.3)$. Thus, we conclude that students who reported cheating on tests during the past term in college were more likely to rely on pre-conventional, self-interested reasoning as compared to more principled reasoning. Normative data suggest that a typical college student has an N2 score of approximately 31-37 with freshmen normally being at the lower end of the scale and seniors at the upper end (Bebeau, 2002). Thus, the 'non-cheater' respondents in this study fall within the normative range for the $N 2$ score, especially considering that the sample is biased toward freshmen. Respondents classified as 'cheaters,' however, have N2 scores that are well below the normative range for college students, even falling slightly below reported mean N2 scores for high school students in grades $10-12$ $($ mean $=31.7)$.

We observed a statistically significant difference in the anti-social scores of 'cheaters'and 'non-cheaters' using the Mann-Whitney test $(Z=-2.171, p=0.03)$. Thus, there is some connection between students who take a negative view of authority, without acknowledging proactive alternatives, and their tendencies to engage in test cheating in college.

Finally, we observed a small, but significant difference in cheating when comparing students consolidated in their moral development versus those in transition (cons/trans). Among participants who were consolidated in a particular stage of moral development, we classified only $26.0 \%$ as 'cheaters.' Transitional respondents, on the other hand, were more often classified as 'cheaters' (35.3\%). This suggests that students who were less consistent in their application of particular moral perspectives were more likely to cheat on tests in college. However, this effect, small as it is, was mitigated by the N2 scores of the respondents. Consolidated respondents had much higher N2 scores than transitional respondents $(t=9.074, d f=367, p<0.001)$. We conclude that consolidated respondents were consistently reasoning at a higher stage of moral development, rather than a lower stage which is equally possible for consolidated individuals. Based on their N2 scores (and others produced by the DIT-2) consolidated respondents appeared to be reliably demonstrating a preference for both a principled reasoning perspective and a maintaining norms perspective (Thoma \& Rest, 1999). Students in transition, however, applied an inconsistent pattern of moral perspectives, vacillating between a personal interest perspective and a maintaining norms perspective.

\section{Decision-Making Variables}

We found significant differences between respondents classified as 'cheaters' and 'non-cheaters' for all of the constructs within the theory of planned behavior at $p=0.02$ or less. Table 3 presents the mean scores of each of the decision-making constructs for both groups of respondents. The scoring of these items was such that higher scores would be related with a decision to cheat on a test. For example, students who reported cheating a few of the times they took a test in the last term of college also indicated that they intended to do so again in the future (intention) by a wide margin. There are similar 
TABLE 3

Comparison of Effect of Classification as 'Cheater' or 'Non-cheater' on the Theory of Planned Behavior Constructs for Decision-making

\begin{tabular}{lcc}
\hline Construct & \multicolumn{2}{c}{ Means } \\
\cline { 2 - 3 } & Cheater & Non-cheater \\
\hline Intention $^{* * * *}$ & 2.55 & 1.49 \\
Attitude $^{* * * *}$ & 2.68 & 1.87 \\
Subjective Norm $^{* * * *}$ & 2.33 & 2.01 \\
Perceived Behavioral Control $^{*}$ & 3.37 & 3.15 \\
Moral Obligation $^{* * *}$ & 2.51 & 1.76 \\
\hline
\end{tabular}

Note. ${ }^{*} \mathrm{p}<0.05,{ }^{* * * *} \mathrm{p}<0.001$

significant differences for attitude, subjective norm, and moral obligation, although the magnitude of the difference is somewhat less.

Based on these results, we conclude that individuals classified as 'cheaters' form more positive attitudes toward cheating on tests, perceive that people important to them are less likely to view them negatively for cheating on tests (subjective norm), and feel less obligation to avoid cheating simply because it is wrong (moral obligation). Perceived behavioral control also exhibited a difference between 'cheaters' and 'non-cheaters' indicating that 'cheaters' have greater confidence in their ability to get away with cheating on a test, regardless of the situational constraints which may exist at the time.

It is not surprising to find such statistically large differences on these constructs between 'cheaters' and 'non-cheaters.' Several previous studies and meta-analyses have provided support for the theory of planned behavior as a model for decision-making for cheating (Beck \& Ajzen, 1991; Harding et al., 2007; Mayhew et al., 2009; Whitley \& Keith-Spiegel, 2002).

\section{REGRESSIONANALYSES}

\section{College Test Cheating}

Using regression analysis we sought to determine the influence of each of the study variables described earlier on the respondents' self-reported frequencies of test cheating in college, and we were particularly interested in understanding why such dramatic differences in college test cheating existed across the three institutions. Because the dependent variable was dichotomous, we used a binary logistic approach to regress the study variables onto the dependent variable of College cheat.

We included only those variables that showed statistically significant differences between 'cheaters' and 'non-cheaters,' as described previously. We did not include the remaining constructs within the theory of planned behavior (attitude, subjective norm, and moral obligation) despite having a demonstrated effect on respondents' self-reported cheating frequency (see Table 3). According to the theory of planned behavior, these constructs are not direct predictors of a behavior, but rather their effect is mitigated through intention (Ajzen, 2002a). This assumption is further supported by previous work we have conducted on this data set and the theory of planned behavior (Mayhew, et al., 2009). 
TABLE 4

Observed and Predicted Frequencies for Test Cheating in College

\begin{tabular}{lccc}
\hline \multirow{2}{*}{ Observed } & \multicolumn{2}{c}{ Predicted } & \\
\cline { 2 - 3 } & Non-Cheater & Cheater & \% Correct \\
\hline Non-cheater & 202 & 27 & $88.2 \%$ \\
Cheater & 36 & 75 & $67.6 \%$ \\
Overall \% Correct & $84.9 \%$ & $73.5 \%$ & $81.5 \%$ \\
\hline
\end{tabular}

Note. False positives: $26.5 \%(n=27)$; False negatives: $15.1 \%(n=36)$

We recoded the variable institution to three dummy variables, each indicating whether a respondent did or did not attend a specific institution in the study. We also selected for removal from the model those respondents who indicated that they were involved in PanHellenic activities more than 20 hours per week. We did this to remove the non-linear nature of this variable, resulting in the removal of 16 respondents or $4.1 \%$ of the total sample. This same selection was conducted for all subsequent analyses described here.

We found that the best regression model was produced using the enter method for variable entry. Goodness-of-fit statistics suggest that the model fit the data reasonably well, with a Nagelkerke R2 value of 0.504 and acceptable Hosmer-Lemeshow statistics $\left(\chi^{2}=6.928, d f=8, p=0.544\right)$ (Peng, Lee \& Ingersoll, 2002). Overall, the model successfully classified $81.5 \%$ of all respondents as either 'cheaters' or 'non-cheaters.' However, as Table 4 shows, the model is clearly more successful at classifying 'non-cheaters' (88.2\%) compared to 'cheaters' (67.6\%). This suggests that the model contains nearly all the variables needed to predict when an individual decides not to cheat on a test but that there remain variables outside the scope of this study that would further explain an individual's decision to cheat on a test in college.

Regression coefficients for the predictor variables included in the model are provided in Table 5. We found two variables that were statistically significant predictors of respondents' engagement in test cheating. Overwhelmingly, the strongest predictor was an individual's intention to engage in test cheating in future terms. A unit increase on this 5-point scale increased the odds that an individual would be classified as a 'cheater' by more than a factor of six. Clearly, individuals who acknowledge cheating on tests in this study were quite certain of their intention to do so again in the coming term. These results are a confirmation of the theory of planned behavior which posits that intention is a direct antecedent to behavior (Ajzen, 2002a).

The model failed to confirm the proposed link between perceived behavioral control and College cheat. The construct of perceived behavioral control is known to have mixed influence on cheating. In a larger study that included non-engineering students, we found no statistical relationship between cheating behavior and perceived behavioral control (Harding et al., 2007). Using the same sample, but applying structural equation modeling to the data, we observed a statistically significant pathway for perceived behavioral control only for those students in the sample who were in a state of moral consolidation, as previously defined, but not for those in moral transition (Mayhew et al., 2009). Others, however, have found strong connections between perceived behavioral control and cheating (Beck \& Ajzen, 1991).

The second strongest predictor was a student's past behavior in high school (HS cheat). We determined that participants who reported cheating on tests in high school were three 
TABLE 5

Regression Coefficients for Binary Logistic Regression of Test Cheating with Odds Ratios for Statistically Significant Predictors

\begin{tabular}{lcccccc}
\hline Variable & $\mathrm{B}$ & $\begin{array}{c}\text { Standard } \\
\text { Error }\end{array}$ & $\begin{array}{c}\text { Wald } \\
\text { Statistic }\end{array}$ & df & Sig. & $\begin{array}{c}\text { Odds } \\
\text { Ratio }\left(\mathrm{e}^{\mathrm{B}}\right)\end{array}$ \\
\hline Constant & -4.487 & 1.867 & 5.776 & 1 & .016 & - \\
Age & -0.042 & 0.072 & 0.343 & 1 & .558 & - \\
$\begin{array}{l}\text { Institution } \\
\text { (Research State) }\end{array}$ & -0.208 & 0.472 & 0.195 & 1 & .659 & - \\
$\begin{array}{l}\text { Institution } \\
\text { (Masters }\end{array}$ & - & - & 0.520 & 2 & .771 & - \\
$\begin{array}{l}\text { University) } \\
\begin{array}{l}\text { Institution (Spe- } \\
\text { cialty Tech) }\end{array}\end{array}$ & 0.089 & 0.411 & 0.047 & 1 & .828 & - \\
$\begin{array}{l}\text { Pan-Hellenic } \\
\text { N2 Score }\end{array}$ & 0.124 & 0.153 & 0.662 & 1 & .416 & - \\
$\begin{array}{l}\text { Anti-social } \\
\text { Cons/Trans }\end{array}$ & -0.017 & 0.013 & 1.633 & 1 & .201 & - \\
$\begin{array}{l}\text { Intention } \\
\begin{array}{l}\text { Perceived } \\
\text { Behavioral }\end{array}\end{array}$ & 0.018 & 0.083 & 0.046 & 1 & .831 & - \\
$\begin{array}{l}\text { Control } \\
\text { HS Cheat } \\
\text { ('non-cheater') }\end{array}$ & 1.854 & 0.264 & 49.421 & 1 & .000 & 6.388 \\
\hline
\end{tabular}

times more likely to be classified as 'cheaters' in college compared to students who reported never cheating on tests during a typical term in high school. We did not, however, find any explanations for the differences in college test cheating across institutions since none of the variables that can be related directly back to the institutional descriptions were identified as predictors. Therefore, we continued with further nested regression analyses.

\section{Intention}

Given that the intention to cheat on a test in the next term in college was such a strong predictor of cheating during the previous academic term, we conducted a further regression of this variable to explore its predictors. Here we used a linear regression model as intention is a normally distributed continuous variable. A simple entry method was used resulting in a model that explained $65.2 \%$ of the variance (adjusted R2) in the data. Regression coefficients are provided in Table 6. As predicted by Ajzen's theory of planned behavior (2002a), the underlying constructs of attitude, subjective norm, and perceived 
TABLE 6

Regression Coefficients for Linear Regression of Intention to Cheat on a Test in the Next Term in College

\begin{tabular}{|c|c|c|c|c|c|}
\hline \multirow{2}{*}{$\begin{array}{l}\text { Model Variables } \\
\text { Blocks }\end{array}$} & \multirow[b]{2}{*}{ Variables } & \multicolumn{2}{|c|}{$\begin{array}{l}\text { Unstandardized } \\
\text { Coefficients }\end{array}$} & \multirow[t]{2}{*}{$\mathrm{t}$} & \multirow{2}{*}{$\begin{array}{c}\text { Standardized } \\
\text { Coefficients } \\
\beta \\
\end{array}$} \\
\hline & & $\mathrm{B}$ & Std. Error & & \\
\hline Constant & & 0.019 & 0.446 & 0.043 & - \\
\hline \multirow[t]{4}{*}{ Demographic } & Age & -0.003 & 0.015 & -0.173 & -0.009 \\
\hline & Sex (Female) & -0.033 & 0.069 & -0.476 & -0.017 \\
\hline & Citizenship (U.S.) & 0.273 & 0.225 & 1.213 & 0.089 \\
\hline & Caucasian (no) & 0.029 & 0.093 & 0.315 & 0.013 \\
\hline \multirow[t]{6}{*}{ Academic } & Institution & -0.035 & 0.043 & -0.822 & -0.032 \\
\hline & $\begin{array}{l}\text { Class Level } \\
\text { (freshmen) }\end{array}$ & -0.006 & 0.075 & -0.080 & -0.004 \\
\hline & Transfer (no) & -0.006 & 0.067 & -0.095 & -0.004 \\
\hline & International (no) & -0.365 & 0.228 & -1.601 & -0.111 \\
\hline & Scholarship & 0.052 & 0.047 & 1.123 & 0.262 \\
\hline & Pan-Hellenic & -0.010 & 0.028 & -0.361 & -0.013 \\
\hline \multirow[t]{3}{*}{ Moral Reasoning } & N2 Score & -0.002 & 0.002 & -0.756 & -0.031 \\
\hline & Anti-social & 0.010 & 0.014 & 0.715 & 0.026 \\
\hline & $\begin{array}{l}\text { Cons/Trans } \\
\text { (transitional) }\end{array}$ & -0.106 & 0.072 & -1.469 & -0.060 \\
\hline \multirow[t]{4}{*}{ Decision-making } & Moral Obligation & 0.351 & 0.044 & 7.999 & $0.421^{* * * *}$ \\
\hline & Subjective Norm & 0.231 & 0.073 & 3.147 & $0.143^{* *}$ \\
\hline & $\begin{array}{l}\text { Perceived Behavioral } \\
\text { Control }\end{array}$ & -0.089 & 0.034 & -2.646 & $-0.102^{* * *}$ \\
\hline & Attitude & 0.111 & 0.039 & 2.875 & $0.136^{* *}$ \\
\hline Past Behavior & $\begin{array}{l}\text { HS Cheat } \\
\text { ('non-cheater') }\end{array}$ & 0.563 & 0.064 & 8.828 & $0.341^{* * * *}$ \\
\hline
\end{tabular}

Note. $* * 0.01, * * 0.001$

behavioral control were all significant predictors of a respondent's intention to cheat on a test in a coming term, agreeing with results from an earlier study (Harding et al., 2007).

Of greater interest here is the fact that the added construct of moral obligation was a stronger predictor of intention than any of the other constructs. This seems to support the notion that decisions to cheat on tests are inherently moral decisions and that moral considerations may be more significant than situational considerations. The regression coefficient for moral obligation was positive because we have coded this scale in such a way that an increase in this scale would predict an increased tendency to intend to cheat per Ajzen's theory.

Further support for the theory of planned behavior comes from the fact that none of the demographic, academic, or moral reasoning variables were significant predictors. Thus, the modified theory and its constructs seem to provide sufficient predictive power 
without added variables, with the one exception of $H S$ cheat. This measure of past cheating was the second strongest predictor of intention, reaffirming the importance of an individual's past experiences with cheating on their present decision-making.

Despite the success in modeling the decision to engage in test cheating using the theory of planned behavior, we again are left without predictor variables that would allow us to explain the discrepancies observed across our three study institutions. Thus, we continue with a further regression analysis of the main predictor variable of intention: moral obligation. We did not carry out a regression of $H S$ cheat as it is a measure of past behavior for which we do not have appropriate predictor variables.

\section{Moral Obligation}

As with intention, the moral obligation scale is a normally distributed, continuous variable. Accordingly, we used a linear regression model with a simple entry method to regress the study variables onto the dependent variable - moral obligation. We did not include the other theory of planned behavior constructs (e.g., attitude, intention, etc.) in this model as they are not expected to predict moral obligation. The resulting model explained $21.5 \%$ of the variance (adjusted R2) in the dependent variable, moral obligation.

Table 7 presents the regression coefficients for the variables included in the model. The strongest predictor of moral obligation for the present study appears to be whether a respondent was classified as a 'cheater' or 'non-cheater' in high school (HS cheat). Once again, past behavior is a strong determinant of present beliefs, attitudes, and behaviors.

Perhaps the most interesting finding was that Pan-Hellenic was a significant predictor of moral obligation. In this case, the standardized coefficient was positive, indicating that the more time a respondent reported spending on Pan-Hellenic activities, the higher they scored on the moral obligation scale. Thus we see that there is an influence of fraternities and sororities on college cheating, but this influence is mitigated through the theory of planned behavior constructs, in particular moral obligation.

Additionally, we found that a respondent's citizenship was a significant predictor of moral obligation. In this case, an individual who was not a citizen of the United States reported a higher moral obligation score (citizen $m=1.97$, non-citizen $m=2.27$ ). Recall that this scale is coded in such a way that a higher score would predict the formation of an intention to cheat in the future. We would predict from these results, therefore, that, for this study, U.S. citizens would express a greater sense of responsibility to avoid cheating. This is an institution-related variable since there were more non-U.S. citizen respondents at Research State than the other institutions (see Table 1).

Finally, anti-social tendencies were found to be a positive predictor of an increased score on the moral obligation score. Thus, the extent to which an individual holds an antiestablishment attitude may contribute to an individual feeling less obligation to avoid cheating. This was not considered an institution-related scale given that there is no statistically significant difference between the study institutions on the anti-social scale.

\section{Discussion}

The goal of this study was to examine the ethical behavior of engineering undergraduates at three institutions within the Midwest region of the United States, and to understand which demographic, academic, moral reasoning, and decision-making variables were predictive of student respondents' self-reported test cheating. In particular we were 
TABLE 7

Regression Coefficients for Linear Regression of Moral Obligation to Avoid Cheating on a Test in the Next Term in College

\begin{tabular}{|c|c|c|c|c|c|}
\hline \multicolumn{2}{|c|}{ Model Variables } & \multicolumn{2}{|c|}{$\begin{array}{l}\text { Unstandardized } \\
\text { Coefficients }\end{array}$} & \multirow[t]{2}{*}{$\mathrm{t}$} & \multirow{2}{*}{$\begin{array}{c}\text { Standardized } \\
\text { Coefficients } \\
\beta\end{array}$} \\
\hline Blocks & Variables & B & Std. Error & & \\
\hline Constant & & 2.384 & 0.668 & 3.568 & - \\
\hline \multirow[t]{4}{*}{ Demographic } & Age & -0.036 & 0.027 & -1.347 & -0.106 \\
\hline & Sex (Female) & -0.195 & 0.118 & -1.656 & -0.087 \\
\hline & Citizenship (U.S.) & 0.794 & 0.394 & 2.016 & $0.221^{*}$ \\
\hline & Caucasian (no) & -0.238 & 0.157 & -1.513 & -0.090 \\
\hline \multirow[t]{6}{*}{ Academic } & Institution & 0.036 & 0.076 & 0.472 & 0.027 \\
\hline & Class Level (freshmen) & 0.167 & 0.129 & 1.290 & 0.089 \\
\hline & Transfer (no) & -0.098 & 0.118 & -0.824 & -0.050 \\
\hline & International (no) & -0.769 & 0.402 & -1.914 & -0.200 \\
\hline & Scholarship & -0.003 & 0.081 & -0.035 & -0.002 \\
\hline & Pan-Hellenic & 0.112 & 0.047 & 2.124 & $0.124^{*}$ \\
\hline \multirow{3}{*}{$\begin{array}{l}\text { Moral } \\
\text { Reasoning }\end{array}$} & N2 Score & -0.007 & 0.004 & -1.699 & -0.102 \\
\hline & Anti-social & 0.064 & 0.025 & 2.527 & $0.131^{*}$ \\
\hline & $\begin{array}{l}\text { Cons/Trans } \\
\text { (transitional) }\end{array}$ & -0.184 & 0.124 & -1.483 & -0.087 \\
\hline Past Behavior & $\begin{array}{l}\text { HS Cheat } \\
\text { ('non-cheater') }\end{array}$ & 0.639 & 0.096 & 6.675 & $0.347^{* * * *}$ \\
\hline
\end{tabular}

Note. ${ }^{*} p<0.05, * * 0.01, * * * 00.001$

interested in identifying variables that might explain observed differences in the selfreported rates of cheating at these institutions.

One finding from this study is that for all three institutions, the self-reported frequency of cheating among respondents went down between high school and college. It is worth noting that we have observed similar reductions in frequency of cheating from high school to college (Harding et al., 2004) with other samples. It is not clear why this change may have occurred; though the most common argument is based on differences in peer disapproval between college and high school (Bowers, 1964; McCabe, Trevino 
\& Butterfield, 2001), and we do not refute or disagree with this perspective. However, there is another explanation based on the data presented here. Participants were asked to retrospectively indicate how frequently they cheated on tests in high school. We noticed that the freshmen respondents were more likely $(Z=-3.139, p=0.002)$ to report cheating on tests in high school than were the senior respondents (54.6\% vs. $37.9 \%$ respectively). However, both groups reported statistically similar levels of test cheating in college $(35.1 \%$ vs. $28.5 \%, Z=-1.326, p=0.185)$. It could be that high school students are now cheating on tests at much higher frequencies than they were a mere four years ago. But it seems unlikely that such a large change would occur in such a short period of time. We believe instead that the seniors, having been removed from their high school years for some time, have simply forgotten the extent to which they cheated in high school. Instead, they may tend to assume that their current behavior mirrors their behavior in high school.

The finding that is at the core of this study, however, is that the reduction in cheating between high school and college is not consistent across the three institutions included in this study. Indeed, respondents from Specialty Tech report cheating at nearly the same frequency in college as they did in high school. We conducted a series of nested regression models to explore this discrepancy. Even though there were observed significant differences in cheating between institutions, institution as a variable was not predictive of either the behavioral outcome or any other outcome variable considered in the nested regression models. Therefore, we conclude that the effect of institution on test cheating is mitigated through other variables not included in our original model (see Figure 2). In particular we propose the inclusion of measures of past high school cheating behavior, involvement in Pan-Hellenic, anti-social tendencies, and an individual's citizenship into a new predictive model of students' decisions to engage in college test cheating, as shown in Figure 5.

The central element of the newly proposed model is still the modified form of Ajzen's theory of planned behavior (Ajzen, 2002a) presented previously in Figure 2. Our results supported inclusion of all of the underlying constructs in the model and all but one of the predicted paths. We take this to be strong support for the use of Ajzen's theory of planned behavior as a predictive model of students' decision-making regarding test cheating in college. This finding is further reinforced by the work of other authors who have found Ajzen's model to be suitable for predicting college student cheating (Beck \& Ajzen, 1991; Generaux \& McLeod, 1995; Whitley, 1998).

It is also noteworthy that moral obligation was found to be an independently predictive antecedent of intention, suggesting that moral considerations are important with regards to decisions made about cheating on tests in college. We found no evidence that students' capacity for moral reasoning, as measured by the DIT-2, has any bearing on decisions to engage in test cheating. This contradicts a well known study in which higher moral reasoning scores, as measured by the original DIT, were strongly related to observed cheating by college students in a laboratory experiment (Malinowski \& Smith, 1985). In our study, we did find that cheating behavior was correlated with the measure used by Malinowski \& Smith (i.e., P-score), but neither this measure, nor the N2 score which we ultimately used, remained an independent predictive variable after regression analysis. As our theoretical framework and the constructs we measured differed from those of Malinowski \& Smith, we can only assume that the influence of moral reasoning as measured by the DIT-2 may not apply to retrospective studies of actual behavior as it did for the laboratory study.

We found no evidence for the existence of the path between perceived behavioral control and the behavioral outcome (College cheat) as originally proposed by Ajzen (2002a), 


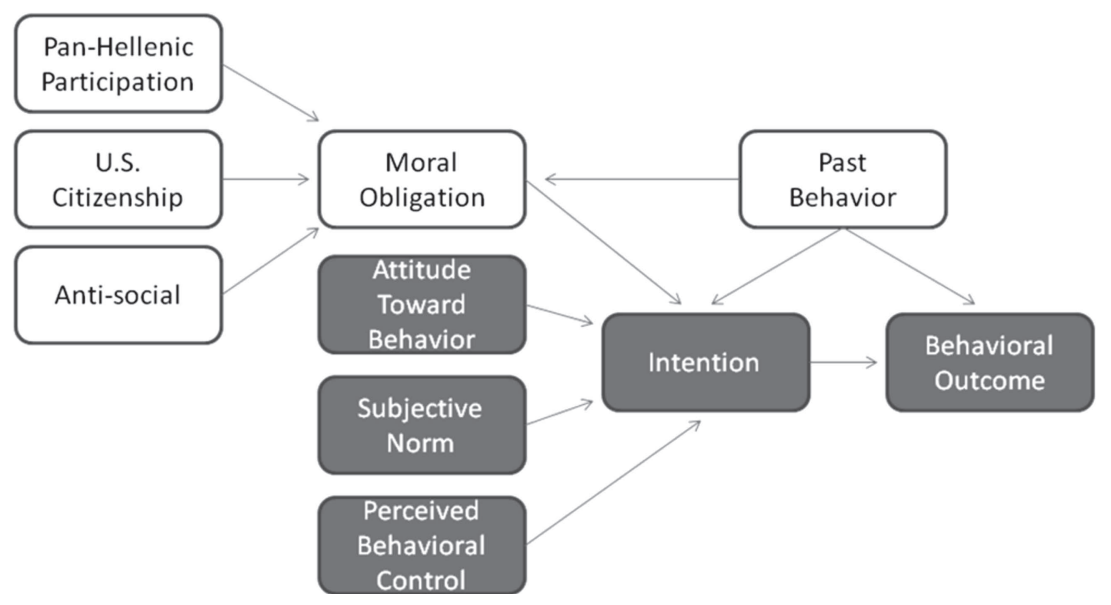

FIGURE 5. Proposed revision of Ajzen's theory of planned behavior for prediction of college test cheating. Ajzen's original theory is shown in the shaded boxes.

though it was related to a student's actual intention to cheat. Similar results were obtained when carrying out a structural equation modeling of a related sample of students (Mayhew et al., 2009). As such, we remove the perceived behavioral control to behavior path from the newly revised model presented here. Removal of this path has profound implications for reducing cheating on college campuses. Efforts to prevent cheating, or catch cheaters, may deter some students from forming an intention to cheat, but for those students who intend to cheat anyway, physical impediments (e.g., separated seating, multiple copies of exams, etc.) are unlikely to have much impact.

Past high school cheating behavior showed up as a significant predictor in each of the regressions; therefore, we include in the new model a direct effect of past behavior on the behavioral outcome (College cheat), intention, and moral obligation. With respect to the behavioral outcome, this is not surprising. In a study examining the ethical decision-making processes of engineering students in college and the workplace (Harding et al., 2004), we observed that the more frequently students reported cheating in high school, the more likely they were to recall a situation in which they decided to cheat as opposed to one in which they did not despite being tempted. In other words, students who frequently cheated in high school are more likely to succumb to future temptations to cheat in college.

What may be most disturbing about the connection between past and present behavior, is that it seems to extend beyond the undergraduate years. Not only did high school cheating correlate to college cheating but it also correlated to the decision to violate the policies of the respondents' workplaces (Harding et al., 2004). A similar result was found by Nonis \& Swift (2001) where business students who engaged in dishonest acts in college classes were more likely to engage in dishonest acts in the workplace. Baldwin, Daugherty, Rowley \& Schwarz (1996) found that the best predictor of cheating in medical school was having cheated previously in one's academic career, either in high school or college. Fass (1990) observed a correlation between cheating in school and cheating on income tax payment, politics and college athletics. 
While it is common to find that past behavior is a strong predictor of future behavior, there is less literature available to explain the relationship between past behavior and the constructs of intention and moral obligation. One explanation may come from the literature on habit formation. Aarts, Verplanken \& van Knippenberg (1998) proposed that the relationship between past behavior and present behavior may be indicative of habit formation. They argued that when a behavior is performed repeatedly it becomes habitual and is guided by automated cognitive processes, rather than by rational decision processes that are assumed to dominate in Ajzen's theory of planned behavior. It is worth noting that Ajzen (2002b) has since argued against habituation as an explanation of the effects of past behavior.

We can speculate that a habit to cheat on tests formed in high school would attain a level of cognitive automaticity to the point that the individual has no rational explanation for why they continue to engage in cheating in college. This might explain why past behavior influences several tested constructs within the theory of planned behavior. An individual's reported behavior, intentions and sense of moral obligation to avoid cheating could all be influenced by a habitual tendency to cheat in a sub-conscious way. Indeed, recent psychological research demonstrates that humans are not purely rational moral agents (Bargh \& Chartrand, 1999; Greene, Morelli, Lowenberg, Nystrom \& Cohen, 2008; Greene, Nystrom, Engell, Darley \& Cohen, 2004; Haidt 2007; Narvaez \& Lapsely, 2005). Though our data is not direct support for a non-rational model of decision-making, it does indicate that future studies may have to take into account the possibility that an assumption of rational decision-making is not valid.

The influence of past behavior may also be an indication that other predictive variables are missing from the model. Beck and Ajzen (1991) argued that an individual's present behavior should only be predicted by past behavior to the extent that the underlying factors have not changed between past and present. If all such underlying factors are known and accounted for within a model, past behavior should fail to be independently predictive. Thus, in the present model where we have included past behavior, we might think of it as a proxy measure of all those factors which are not yet known or accounted for.

The one factor besides past behavior that seemed to strongly relate to increased cheating was Pan-Hellenic. We reported previously that, for the sample overall, the more a student participates in fraternity or sorority activities, the more they reported cheating. One explanation for this relationship is that as students spend more time on these activities, they find it more difficult to keep up with their studies and turn to cheating. On the other hand, students who spend more than 20 hours per week likely represent dedicated leaders within these organizations. As such, these respondents may be high achieving, academically motivated students who find little need to cheat and/or who do not want to jeopardize their role as leaders by engaging in academic dishonesty.

The tendency for Pan-Hellenic members to report higher levels of cheating is nothing new. Bowers (1964) first reported higher levels of cheating among fraternity members, and, based on the available evidence, suggested that it was participation in fraternity activities that led to cheating rather than self-selection of cheaters into fraternities. Bowers did not investigate the behavior of sorority members. Numerous studies since this time have confirmed the general view that Pan-Hellenic membership is associated with increased cheating (Diekhoff, LaBeff, Clark, Williams, Francis \& Haines, 1996; Haines, Diekhoff, LaBeff \& Clark, 1986; McCabe \& Trevino, 1997; Moffat, 1990). This view is further extended by the data presented here, as time spent on Pan-Hellenic activities, not just 
membership, was found to be an independent predictor of college test cheating even after past behavior was accounted for.

Pan-Hellenic membership has generally been viewed as a contextual variable because these organizations are thought to provide a social context in which cheating is more likely. Eve and Bromley (1981) argued that fraternities promote a social orientation in which the norms promote academic dishonesty over intellectual curiosity. Greek organizations are learning environments where norms, values, and skills associated with cheating can be more easily transmitted. According to social learning theory (Bandura, 1986), students involved in fraternities and sororities would observe from their peers what behaviors are most likely to be approved or disapproved. In this way, peer approval of cheating becomes a self-reinforcing influence on students' decisions about engaging in cheating. Within these data, we see that the influence of Pan-Hellenic membership is mitigated through moral obligation. Keeping in mind the limitations of this study including a lack of measures for other non-academic activities, it may be the case that the social context of PanHellenic organizations creates a norm in which students learn from their peers that they have little or no moral obligation to avoid cheating.

Our revised model also includes a predictive path between one's citizenship status (U.S. or non-U.S.) and moral obligation. Such a finding may point to cultural differences in perceptions about an individual's duty to avoid cheating between these groups of students (Hall and Kuh, 1998; Kuehn, Stanwyck \& Holland, 1990; Magnus, Polterovich, Danilov \& Savvateev, 2002). The tendency of non-U.S. citizens to report less moral obligation to avoid cheating may also be related to a sense of alienation at college. Alienation is a psychological state in which the individual feels removed from their own culture through social isolation. We might expect that non-U.S. citizens may feel a certain degree of alienation while attending a U.S. institution. Whitley (1998) has shown that alienation is moderately related to increased levels of cheating in college students.

Though there were differences in numbers of non-U.S. citizens across the three institutions in this study (Research State had by far the largest percentage), there was no correlation between numbers of non-U.S. citizens and increased cheating as would be expected based on the above discussion. In fact, Research State reported the lowest levels of college cheating overall. Interestingly, the variable international was not related to moral obligation as citizenship was despite the fact that these two variables would be expected to correlate strongly.

The last construct found to influence student decision making regarding test cheating was an anti-social orientation. Anti-social individuals typically fault existing authorities for being hypocritical and are critical of the conventional social order, without offering positive alternatives (Bebeau \& Thoma, 2003). It is uncertain why anti-social tendencies would be related to a reduced moral obligation to avoid cheating, as was found in this study. We might speculate that individuals with anti-social attitudes would believe themselves to have little obligation to avoid cheating in an educational system where the faculty and administration are seen as "hypocritical elites."

Though we believe that the results of this study are essentially valid, there are some limitations. First, self-reporting may be subject to social desirability response bias (e.g., Zimny, Readhead \& Heckman, 1996). Therefore, the prevalence statistics reviewed may be underestimates of the actual cheating rates. To avoid this, all responses were collected anonymously. Additionally, we included the Balanced Inventory of Desirable Responding (Paulhus, 1991) in our survey instrument as a control. Though respondents were no more likely to respond in a socially desirable way than would be expected from national norms, 
we cannot be certain that individuals did not alter their responses so as to appear more positive in the eyes of the researchers. Second, there is some evidence to suggest that the theory of planned behavior is more predictive of self-reported behavioral data than of actual observed behavior (Armitage \& Conner, 2001). While direct observation of behavior would be ideal, there are significant ethical and practical challenges to directly observing students engaging in cheating behaviors. Thus, we are left to assume that our self-report instruments are sufficient for our purposes.

\section{Conclusions}

Even though reported cheating varied between the three institutions, we showed through regression analysis that institution as a variable was not significant. It is not the institution type that is important, but rather the contextual factors that describe the cultures of these institutions that matter. Therefore, an exploratory analysis of the institutional factors that would explain observed differences in the self-reported rates of undergraduate engineering cheating at the three universities was the focus of this investigation. This analysis included demographic, academic, moral reasoning, and decision-making predictor variables of the behavioral outcome variable of college test cheating. A modified form of the theory of planned behavior served as a theoretical framework for students' process for making decisions with regards to college cheating. We describe four main findings.

First, we found that students' past cheating in high school had a strong influential effect on their decisions to cheat in college, though it did not explain the observed behavioral differences between institutions. Though one cannot screen out students for having cheated in the past, institutions of higher education are encouraged to have frank conversations with students about cheating in high school and the change in expectations for college especially as it relates to being a future professional.

Second, students who reported cheating on tests in high school felt less moral obligation to avoid cheating in college, cheated on tests more frequently in college, and were more likely to intend to cheat again in the future. Though more research is needed to better operationalize moral obligation, it at least provides us with a direction for possible interventions to reduce cheating. College is recognized as a highly influential period in a person's moral development (King \& Mayhew, 2002; Pascarella \& Terenzini, 2005) with greater moral gains representing an opportunity to curb undesirable cheating behavior. To increase moral development, students can be encouraged to participate in community service activities, civic organizations, service learning projects, engineering design teams, student governance, campus judiciary systems, and other student-led organizations. Furthermore, students can also be encouraged to take on leadership positions in these organizations since students themselves often see leadership as a distinguishing feature of an individual's ethical development in college (Sutkus, Carpenter, Finelli \& Harding, 2009). Interestingly, such co-curricular activities may serve not only to promote moral obligation, but also serve as means to partially address other professional skills required by ABET such as teamwork, lifelong learning, etc.

Third, we found that participation in Pan-Hellenic groups was a strong differentiating predictor between the three universities, as evidenced by the large membership and high rates of self-reported cheating at Specialty Tech. In general, the more actively students were involved in fraternities or sororities, the more frequently they cheated (except for the 
most active). Interestingly, fraternity membership did not appear to directly affect students' cheating behavior or their intentions to cheat in the future. Rather, it reduces their sense of a moral obligation to avoid cheating, which in turn, alters intention formation and behavior. We concluded from this that Pan-Hellenic organizations create a social environment in which the moral norms position cheating as an acceptable behavior. This could be addressed through proactively working with interfraternity councils on expectations of membership.

Finally, we found that perceived behavioral control had little influence on actual behavior. This suggests that faculty consider balancing the effort they place on physical impediments to cheating with efforts to influence students' moral obligation to avoid cheating. Though impediments have their place, and their complete removal would probably be an unwise decision, we have found that draconian environments rarely have the impact faculty assume they will. Often, better results can be obtained by creating a caring, student-centered environment, where students come to believe that cheating is against the social norms of their learning community and their own self-interest.

\section{ACKNOWLEDGMENTS}

The authors would like to thank the John Templeton Foundation and the Kern Family Foundation for their financial support of this work. We also wish to thank the students who participated in this study and Matthew Mayhew who assisted with data collection and analysis.

\section{REFERENCES}

Aarts, H., Verplanken, B., \& van Knippenberg, A. (1998). Predicting behaviors from actions in the past: Repeated decision making or a matter of habit? Journal of Applied Social Psychology, 28(15): 1355-1374.

Adams, R., Fortenberry, S., Haghighi, K., Imbrie, P. K., Jamieson, L., Lohmann, . . . Smith, K. (2006). Special Report: The research agenda for the new discipline of engineering education. Journal of Engineering Education, 95(4), 259-261.

Ajzen, I. (1991). The theory of planned behavior. Organizational Behavior and Human Decision Processes, 50, 179-211.

Ajzen, I. (2002a). Attitudes, personality, and behavior. Buckingham: Open University Press.

Ajzen, I. (2002b). Residual effects of past on later behavior: Habituation and reasoned action perspectives. Personality and Social Psychology Review, 6(2): 107-122.

Armitage, C. J., \& Conner, M. (2001). Efficacy of the theory of planned behavior: A metaanalytic review. British Journal of Social Psychology, 40, 471-499.

American Society for Engineering Education. (2003). Profiles of engineering and engineering technology colleges. American Society for Engineering Education: Washington, D.C.

Baldwin, D. C., Jr., Daugherty, S. R., Rowley, B. D., \& Schwarz, M. D. (1996). Cheating in medical school: a survey of second-year students at 31 schools. Academic Medicine, 71(3), 267-273.

Bandura, A. (1986). Social foundations of thought and action: A social cognitive theory. Englewood Cliffs, NJ: Prentice Hall. 
Bargh, J. A., \& Chartrand, T.L. (1999, July). The unbearable automaticity of being. American Psychologist, 54(7): 462-479.

Bargh, J. A., \& Fergunson, M. J. (2000). Beyond behaviorism: On the automaticity of higher mental processes. Psychological Bulletin, 126(6) 925-945.

Bebeau, M. J. (2002). The defining issues test and the four component model: Contributions to professional education. Journal of Moral Education, 31(3): 271-295.

Bebeau, M. J., \& Thoma, S. J. (2003). Guide for DIT-2: A guide for using the Defining Issues Test, Version 2 ("DIT-2") and the Scoring. Minneapolis, MN: Center for the Study of Ethical Development.

Beck, L. \& Ajzen, I. (1991). Predicting dishonest actions using the theory of planned behavior. Journal of Research in Personality, 25(3), 285-301.

Bowers, W. J. (1964). Student dishonesty and its control in college. New York, NY: Bureau of Applied Social Research, Columbia University.

Carnegie Foundation for the Advancement of Teaching. (2009). The Carnegie Classification of Institutions of Higher Education. Retrieved from www.carnegiefoundation.org/classifications/index.asp

Carpenter, D. D., Harding, T. S., Finelli, C. J., Montgomery, S. M., \& Passow, H. J. (2006). Engineering students' perceptions of and attitudes towards cheating. Journal of Engineering Education, 95(3), 181-194.

Conner, M., \& Armitage, C. J. (1998). Extending the theory of planned behavior: A review and avenues for further research. Journal of Applied Social Psychology, 28(15), 1429-1464.

Diekhoff, G. M., LaBeff, E. E., Clark, R. E., Williams, L. E., Francis, B., \& Haines, V.J. (1996). College cheating: Ten years later. Research in Higher Education, 37(4), 487-502.

Eve, R. A., \& Bromley, D. G. (1981). Scholastic dishonesty among college undergraduates: Parallel tests of two sociological explanations. Youth E Society, 13(1), 3-22.

Fass, R. A. (1990). Cheating and plagiarism. In W.W. May (Ed.), Ethics and higher education (pp. 170-184). New York, NY: Macmillan.

Finelli, C. J., Harding, T. S. \& Carpenter, D. D. (2007, June). Academic integrity among engineering undergraduates: Seven years of research. Proceedings of the 2007 ASEE Annual Conference E Exposition, Honolulu, HI.

Finelli, C. J., Szwalek, J. L., Harding, T. S., \& Carpenter, D. D. (2005, Oct.). A case study of research in engineering education: Designing, testing, and administering the PACES-2 Survey on academic integrity. Proceedings of the 35th Frontiers in Education Conference, Indianapolis, IN.

Generaux, R. L., \& McLeod, B. A. (1995). Circumstances surrounding cheating: A questionnaire study of college students. Research in Higher Education, 36(6), 687-704.

Greene, J. D., Morelli, S. A., Lowenberg, K., Nystrom, L. E. \& Cohen, J. D. (2008). Cognitive load selectively interferes with utilitarian moral judgment. Cognition, 107(3), 1144-1154.

Greene, J. D., Nystrom, L. E., Engell, A. D., Darley, J. M., \& Cohen, J. D. (2004). The neural bases of cognitive conflict and control in moral judgment. Neuron, 44(2), 389400.

Haidt,J. (2007). The new synthesis in moral psychology. Science, 316(5827), 998-1002. 
Haines, V.J., Diekhoff, G. M., LaBeff, E. E., \& Clark, R. E. (1986). College cheating: Immaturity, lack of commitment, and the neutralizing attitude. Research in Higher Education, 25(4), 342-354.

Hall, T. L., \& Kuh, G. D. (1998). Honor among students: Academic integrity and honor codes at state-assisted universities. NASPA Journal, 36(1), 2-18.

Harding, T. S., Carpenter, D. D., Finelli, C. J., \& Passow, H. J. (2004). Does academic dishonesty relate to unethical behavior in professional practice? An exploratory study. Science and Engineering Ethics, 10, 311-324.

Harding, T. S., Finelli, C. J., Carpenter, D. D., \& Mayhew, M. J. (2006, June). Examining the underlying motivations of engineering undergraduates to behave unethically. Proceedings of the 2006 ASEE Annual Conference E' Exposition, Chicago, IL.

Harding, T. S., Mayhew, M. J., Finelli, C. J., \& Carpenter, D. D. (2007). The theory of planned behavior as a model of academic dishonesty in humanities and engineering undergraduates. Ethics and Behavior, 17(3), 255-279.

King, P., \& Mayhew, M. J. (2002). Moral judgment development in higher education: Insights from the Defining Issues Test. Journal of Moral Education, 31(3), 247-270.

Kohlberg, L. (1981). The philosophy of moral development: Moral stages and the idea of justice. New York, NY: Harper Collins.

Kuehn, P., Stanwyck, D. J., \& Holland, C. L. (1990). Attitudes toward "cheating" behaviors in the ESL classroom. TESOL Quarterly, 24(2), 313-317.

Magnus, J. R., Polterovich, V. M., Danilov, D. L., \& Savvateev, A. V. (2002). Tolerance of Cheating: An analysis across countries. The Journal of Economic Education, 33(2), 125-135.

Malinowski, C. I., \& Smith, C.P. (1985). Moral reasoning and moral conduct: An investigation prompted by Kohlberg's theory. Journal of Personality and Social Psychology, 49(4), 10161027.

Mayhew, M. J., Hubbard, S. M., Finelli, C. J., Harding, T. S., \& Carpenter, D. D. (2009). Using structural equation modeling to validate the theory of planned behavior as a model for predicting student cheating. Review of Higher Education, 32(4), 441-468.

McCabe, D. L., \& Trevino, L. (1997). Individual and contextual influences on academic dishonesty: A multicampus investigation. Research in Higher Education, 38(3), 379-396.

McCabe, D. L., Trevino, L., \& Butterfield, K. D. (2001). Cheating in academic institutions: A decade of research. Ethics and Behavior, 11(3), 219-232.

Moffat, M. (1990). Undergraduate cheating. New Brunswick NJ: Rutgers State University.

Narvaez, D. \& Lapsely, D. K. (2005). The psychological foundations of everyday morality and moral expertise. In D. K. Lapsely \& F.C. Power (Eds.), Character psychology and character education, (pp. 140-165). Notre Dame, IN: University of Notre Dame Press.

National Academy of Engineering. (2003). Emerging technologies and ethical issues in engineering. Washington, DC: National Academies Press.

National Academy of Engineering (2004). The engineer of 2020: Visions of engineering in the new century. Washington, DC: National Academies Press.

National Science Foundation. (2006). Investing in America's future-National Science Foundation Strategic Plan FY 2006-2011. Retrieved from http://www.nsf.gov/publications/pub_summ. jsp?ods_key=nsf0648 
Nonis, S. A., \& Swift, C. O. (2001). An examination of the relationship between academic dishonesty and workplace dishonesty: A multicampus investigation. Journal of Education for Business, 77(2), 69-77.

Pascarella, E. T., \& Terenzini, P.T. (2005). How college affects students. Vol.2: A third decade of research. San Francisco, CA: Jossey-Bass.

Passow, H. J., Mayhew, M. J., Finelli, C. J., Harding, T. S., \& Carpenter, D. D. (2006). Factors influencing engineering students' decisions to cheat by type of assessment. Research in Higher Education, 47(7), 643-684.

Paulhus, D. L. (1991). Measurement and control of response bias. In J. P. Robinson, P. R. Shaver, \&L. S. Wrightman (Eds.), Measures of personality and social psychological attitudes (pp. 17-59). San Diego, CA: Academic Press, Inc.

Peng, C. J., Lee, K. L., \& Ingersoll, G. M. (2002). An introduction to logistic regression analysis and reporting. Journal of Educational Research, 96(1), 3-14.

Rest, J. R., \& Narvaez, D. (1994). Moral development in the professions: Psychology and applied ethics. Hillsdale, NJ: Lawrence Erlbaum Associates.

Rest, J. R., \& Narvaez, D. (1998). Guide for DIT-2. Minneapolis, MN: Center for the Study of Ethical Development, University of Minnesota.

Rest, J. R., Narvaez, D., Thoma, J., \& Bebeau, M. J. (1999). DIT2: Devising and testing a revised instrument of moral judgment. Journal of Educational Psychology, 89(1), 5-28.

Rogers, G. (2002). Rethinking moral growth in college and beyond. Journal of Moral Education, 31(3), 325-338.

Sheppard, S., Macatangay, K., Colby, A., \& Sullivan, W. (2009). Educating engineers. Design for the future of the Field. Carnegie Foundation for the Advancement of Teaching. San Francisco: Jossey-Bass.

Sutkus, J. A., Finelli, C. J., Carpenter, D. D., \& Harding, T. S. (2009). An examination of student experiences related to engineering ethics: Initial findings. Proceedings of the 2009 ASEE Annual Conference E' Exposition, Austin, TX.

Thoma, S. J., \& Rest, J. R. (1999). The relationship between moral decision making and patterns of consolidation and transition in moral judgment development. Developmental Psychology, 35(2), 323-334.

Whitley, Jr., B. E. (1998). Factors associated with cheating among college students: A review. Research in Higher Education, 39(3), 235-274.

Whitley, Jr., B. E., \& Keith-Spiegel, P. (2002). Academic dishonesty: An educator's guide. Mahwah, NJ: Lawrence Erlbaum Associates.

Zimny, S. T., Readhead, T., \& Heckman, K. (1996, March). Predictors of dishonest behaviors across domains. Paper presented at the meeting of the Eastern Psychological Association, Philadelphia.

\section{AuTHORS}

Trevor S. Harding, Ph.D., is chair and professor of Materials Engineering, California Polytechnic State University, Bldg. 41-229, 1 Grand Avenue, San Luis Obispo, CA 93407; tharding@calpoly.edu. 
Donald D. Carpenter, Ph.D., P.E., LEED AP is associate professor of Civil Engineering, Lawrence Technological University, 21000 W. Ten Mile, Southfield, MI 480751058; carpenter@1tu.edu.

Cynthia J. Finelli, Ph.D. is director of the Center for Research on Learning and Teaching in Engineering and research associate professor of Engineering Education, University of Michigan, 208 Gorguze Family Laboratory, 2609 Draper Drive, Ann Arbor, MI 48109-2101; cfinelli@umich.edu. 